\title{
Mycorrhization of Quercus mongolica seedlings by Tuber melanosporum alters root carbon exudation and rhizosphere bacterial communities
}

\author{
Yanliang Wang (D) Ran Wang $\cdot$ Bin Lu $\cdot$ Alexis Guerin-Laguette • \\ Xinhua He $\cdot$ Fuqiang Yu
}

Received: 5 April 2021 / Accepted: 29 July 2021 / Published online: 11 August 2021

(C) The Author(s), under exclusive licence to Springer Nature Switzerland AG 2021

\begin{abstract}
Aims To study how ectomycorrhizas (ECMs) mediate plant performance and rhizosphere soil bacterial communities via altered physiological characteristics and root carbon exudation.
\end{abstract}

Responsible Editor: Felipe E. Albornoz, Hans Lambers

Supplementary Information The online version contains supplementary material available at https://doi. org/10.1007/s11104-021-05112-7.

Y. Wang $(\bowtie) \cdot$ R. Wang $\cdot$ B. Lu · A. Guerin-Laguette

X. He $\cdot$ F. Yu $(\bowtie)$

The Germplasm Bank of Wild Species, Yunnan Key

Laboratory for Fungal Diversity and Green Development,

Kunming Institute of Botany, Chinese Academy

of Sciences, Kunming 650201, Yunnan, China

e-mail: wangyanliang@mail.kib.ac.cn

F. Yu

e-mail: fqyu@mail.kib.ac.cn

R. Wang

Department of Crop and Forest Science, University of Lleida, Av. Alcalde Rovira Roure, 191, 25198 Lleida, Spain

X. He

Department of Land, Air and Water Resources, University of California at Davis, Davis, CA 95616, USA

X. He

School of Biological Sciences, University of Western

Australia, Perth, WA 6009, Australia
Methods Tuber melanosporum-colonized and uncolonized Quercus mongolica seedlings were grown on a substrate consisting of $41 \%$ peat, $41 \%$ pumice, $9 \%$ pine bark and $9 \%$ lime. Gas exchange fluorescence system, inductively coupled plasma atomic-emission spectrometer, high-performance liquid chromatography, gas chromatography and mass spectrometry, and 16S rRNA sequencing were used to analyze photosynthetic and nutritional characteristics, rhizosphere carbon exudates, and bacterial communities.

Results Tuber melanosporum mycorrhization increased leaf photosynthetic rate (69\%), phosphorus concentration (94\%), rhizosphere $\mathrm{pH}$ (0.4 units), rhizosphere acid phosphatase activity (33\%) and total organic carbon $(76 \%)$ in rhizosphere extracts but decreased leaf potassium concentration (26\%) and rhizosphere organic anions (50\%). Additionally, sugars including galactose were present in rhizosphere extract of colonized, but not uncolonized seedlings. Mycorrhization altered rhizosphere bacterial communities, with only $10 \%$ operational taxonomic units (OTUs) shared between colonized and uncolonized seedlings; T. melanosporum colonized plants were enriched in actinobacteria. The differential abundances of other bacterial OTUs affected by T. melanosporum colonization were also correlated with variation in plant physiological and/or rhizosphere factors. Conclusion Our results suggest that T. melanosporum ECM colonization may regulate carbon economy and rhizosphere bacterial communities of $Q$. 
mongolica seedlings grown in a previously sterilized peat-based substrate, to promote plant growth and nutrient cycling.

Keywords Carbon assimilation - Ectomycorrhiza . Oak $\cdot$ Peat $\cdot$ Périgord black truffle

\section{Introduction}

In temperate and boreal forests ectomycorrhizas (ECMs) are often symbiotically formed between trees and soil fungi. Typically, ECMs develop as short lateral roots covered in a thick mantle made of fungal hyphae, some of which penetrate the epidermis and grow between cortical cells forming the Hartig net (Peterson et al. 2004), the site where plant and fungal symbionts exchange water and mineral nutrients from fungi for carbon (C) from plants (Smith and Read 2008). ECMs produce extra-radical mycelia that emanate from the mantle surface into their surrounding soil to absorb nutrients and then transfer them to their host plants (Anderson and Cairney 2007). ECMs can also release $\mathrm{C}$ and nitrogen $(\mathrm{N})$ exudates including amino acids, organic acids and enzymes to mobilize plant less-available nutrients. In this way ECMs promote soil $\mathrm{C}$ and other nutrients cycling, as well as plant nutrients uptake (Smith and Read 2008; Cairney 2011; Wang and Lambers 2020).

Plants have evolved various strategies (e.g., changes in root architecture, root exudates and root symbionts) to improve nutrient acquisition, whilst they are likely to exhibit trade-offs in photosynthetically assimilated $\mathrm{C}$ allocation among different adaptive strategies (Wang and Lambers 2020). Root symbiosis with soil mycorrhizal fungi and increased root exudates are two responses to low $\mathrm{P}$ availability and both strategies increase plant $\mathrm{P}$ acquisition at significant C cost (Lynch et al. 2005; Raven et al. 2018). Hence, plant roots colonized by mycorrhizal fungi may result in decreased root-exuded organic anions (e.g., Ryan et al. 2012; Nazeri et al. 2013). In addition, root exudates such as organic anions and amino acids are a key factor shaping rhizosphere bacterial communities (Landi et al. 2006; Haichar et al. 2014; Zhalnina et al. 2018), and considerable evidence indicates that soil bacterial communities play important roles in plant resistance to biotic and abiotic stress (Bulgarelli et al. 2013). To date, the effects of ECMs on root-released organic anions have been tested in a few studies but showed contrasting results (Casarin et al. 2004; van Scholl et al. 2006; Cairney 2011; Meier et al. 2013). There are still few studies on ECM-associated bacterial communities (Nguyen and Bruns 2015). Moreover, current precepts on the function of mycorrhizas are mainly based on experimental data of studies using limited species under certain conditions, hereby researchers are encouraged to revisit mycorrhizal dogmas, especially for their non-nutritional benefits (Albornoz et al. 2021). Therefore, ECM-associated $\mathrm{C}$ exudation and its effects on soil bacterial structure warrant further study.

Tuber melanosporum, the Périgord black truffle, is probably the most economically important truffle species in Europe (Donnini et al. 2013), but it is not naturally present in China. However, truffle plantations have been established with $T$. melanosporum worldwide (Donnini et al. 2013), including China, which has T. melanosporum plantations in Guizhou, Yunnan and Sichuan Provinces (Wang 2012). Although T. melanosporum ECM synthesis and cultivation have made great progress, there are still few studies focusing on the effect of T. melanosporum colonization on physiological processes of in the host rhizosphere. We recently reported that $T$. melanosporum can colonize Quercus species indigenous to China (Wang et al. 2019). Interestingly, $Q$. mongolica showed the highest mycorrhizal receptivity and stability as well as accelerated bud-break and vigorous growth under greenhouse conditions However, the underlying eco-physiological mechanisms of $T$. melanosporum-promoted host growth remain poorly explored.

The objective of this study was to determine the response of plant photosynthetic parameters, nutrient acquisition, root $\mathrm{C}$ exudation and rhizosphere bacterial communities to ectomycorrhizal colonization of $Q$. mongolica by T. melanosporum. We hypothesized that (1) as a mutually beneficial symbiosis, T. melanosporum mycorrhization will promote leaf photosynthetic rate and increase nutrient concentration of Q. mongolica seedlings; (2) T. melanosporum mycorrhization will reduce the amounts of rhizosphere $\mathrm{C}$ exudates (e.g. organic anions) due to $\mathrm{C}$ trade-offs; (3) The change in rhizosphere $\mathrm{C}$ exudates by $T$. melanosporum mycorrhization will alter the bacterial community structure in the rhizosphere. 


\section{Materials and methods}

Plant material and ectomycorrhizal synthesis

The same seedlings reported by Wang et al (2019) were used in this study, where detailed information on plant cultivation and ECM synthesis can be obtained. Briefly, sterilized and sprouted seeds of $Q$. mongolica (obtained from the Germplasm Bank of Wild Species, Kunming, China) were transplanted into a sterilized mixture of perlite and vermiculite (50:50, v:v) in an environment-controlled indoor chamber. After eight months, seedlings (all free of ECMs) of similar size were selected, water washed and transplanted to sterilized growth media (peat: pumice: pine bark: lime $=9: 9: 2: 2$, v: v; $\mathrm{pH} 8.0$, an optimum $\mathrm{pH}$ for $T$. melanosporum growth), where the roots of each seedling were inoculated with $10 \mathrm{~mL}$ (about $1.5 \times 10^{8}$ spores) of T. melanosporum spore slurry (ascocarps sourced from Canterbury, New Zealand). This substrate is, to our experience, favorable to ECM synthesis and acclimation (Wang et al. 2019). The plants were grown in a greenhouse at the Kunming Institute of Botany under natural light; and after three months of inoculation, each pot was fertilized with $2.5 \mathrm{~mL}$ of slow-release Osmocote ${ }^{\circledR} 5$ (ICL SF USA and Canada, Summerville, SC, USA, sold by Lily's gardening in Shanghai) (Crowley et al.1986; Guerin-Laguette et al. 2014), which contained $14 \% \mathrm{~N}\left(5.5 \% \mathrm{NO}_{3}-\mathrm{N}+8.5 \%\right.$ $\left.\mathrm{NH}_{4}-\mathrm{N}\right), 13 \% \mathrm{P}\left(\mathrm{P}_{2} \mathrm{O}_{5}\right)$ and $13 \% \mathrm{~K}\left(\mathrm{~K}_{2} \mathrm{O}\right)$. Ectomycorrhizal development was monitored 6, 9, 12, 24 and 32 months after inoculation, respectively. To identify $T$. melanosporum ECMs, the whole root system was carefully taken from the pot and placed in a tray for macro-morphological examination by a stereomicroscope (Leica S8AP0), and then their anatomical characters were confirmed from 2 to 3 tips per seedling using a compound light microscope (LeicaDM2500). Next, 3-5 colonized root tips from each plant were sampled for DNA extraction and the internal transcribed spacer (ITS) region of the ribosomal DNA was amplified using the ITS1F/ITS4 primer pair. PCR products were Sanger sequenced and queried against published references of the NCBI public database GenBank. All control and inoculated seedlings were checked by both morphological and molecular methods each time. Tuber melanosporum ECMs were successfully produced on all five inoculated seedlings six months after inoculation, and fresh mycorrhizas were constantly observed over at least 32 months. In addition, no contaminant mycorrhizal species were detected, and the DNA extracts of $Q$. mongolica mycorrhizas produced a single $T$. melanosporum-specific $440 \mathrm{bp}$ fragment (Wang et al. 2019). Samplings for the present study were performed 37 months after inoculation in August 2019 when fresh T. melanosporum ECMs were still present. Four mycorrhizal and four non-inoculated control seedlings $(n=4)$ were used for this study (compared to other four seedlings with similar growth size, one smaller seedling from both the non-mycorrhizal and mycorrhizal treatment was not sampled for any parameter measurement).

Measurement of leaf photosynthetic parameters and nutrients concentration

A portable gas exchange fluorescence system GFS3000 (Heinz Walz GmbH, Effeeltrich, Germany) was used to measure the photosynthetic rate $(A)$, transpiration rate $(E)$, stomatal conductance $\left(\mathrm{GH}_{2} \mathrm{O}\right)$ and intercellular $\mathrm{CO}_{2}$ concentration $(\mathrm{Ci})$ in mature leaves (fully expanded, the 2nd top leaf) between 10:00 am and 11:30 am, under photosynthetic active light intensity of $1000 \mu \mathrm{mol} \mathrm{m} \mathrm{m}^{-2} \mathrm{~s}^{-1}$ on the upper leaf area. In the measuring head, the external $\mathrm{CO}_{2}$ concentration, the temperature and relative air humidity were $400 \mathrm{ppm}, 25{ }^{\circ} \mathrm{C}$ and about $60 \%$, respectively. Photosynthetic parameters were evaluated every 3 min until readings were stable, and values of $A, E, \mathrm{GH}_{2} \mathrm{O}$, and $\mathrm{Ci}$ were then recorded.

Two mature leaves from each seedling were sampled. Fresh and dry $\left(65^{\circ} \mathrm{C}\right.$ for $\left.48 \mathrm{~h}\right)$ weights as well as leaf water contents were determined. The dry leaves were ground into fine powders, which were pulverized to pass through a $0.25 \mathrm{~mm}$ sieve. Leaf carbon (C) and nitrogen $(\mathrm{N})$ were determined by a Vario MAX $\mathrm{CN}$ instrument (Elementar Analyse system $\mathrm{GmbH}$, Germany). For element determination, the powders were digested with concentrated $\mathrm{HNO}_{3}-\mathrm{HClO}_{4}$, and total phosphorus $(\mathrm{P})$, potassium $(\mathrm{K})$, calcium $(\mathrm{Ca})$, magnesium $(\mathrm{Mg})$ and iron $(\mathrm{Fe})$ were determined with an inductively coupled plasma atomic-emission spectrometer (IRIS Advantage-ER; Thermo Jarrell Ash Corporation, Franklin, MA, USA). 
Determination of rhizosphere $\mathrm{pH}$, phosphatases activity and exudates

The intact seedlings were carefully taken out from pots and roots were gently shaken to remove excess growth media. The growth medium remaining attached to the roots was defined as rhizosphere substrate (Wang et al. 2016). For each plant, about $2 \mathrm{~g}$ rhizosphere fresh growth medium were carefully sampled using tweezers and spoons, and were then divided into two parts, one was stocked at $-20{ }^{\circ} \mathrm{C}$.for DNA extraction and another was airdried at room temperature for phosphatases activity measurements. The activities of rhizosphere acid or alkaline phosphatase (S-ACP or S-ALP) were separately measured using their respective kit (Solarbio®, Beijing, China), following the manufacturer's instructions.

After the subsampling of rhizosphere growth medium, the entire root system with the remaining rhizosphere growth medium was transferred into a flask containing $150 \mathrm{~mL} 0.2 \mathrm{mM} \mathrm{CaCl}_{2}$ solution to ensure cell integrity. Roots were then gently and carefully dunked for $150 \mathrm{~s}$ to get rhizosphere extract (Pang et al. 2015; Wang et al. 2016). Then the roots were removed, the flasks were shaken by hand, and the extract $\mathrm{pH}$ (diluted samples, which might underestimate the $\mathrm{pH}$ on the root surface) was measured (Wang et al. 2017). Next, $0.01 \mathrm{~g} \mathrm{~L}^{-1}$ Micropur (Katadyn Products, Kemptthal, Switzerland) was added to the extract to inhibit the activity of microorganisms.

A subsample of the rhizosphere extract was centrifuged, and the supernatant was filtered through a $0.45 \mu \mathrm{m}$ membrane filter and was assessed using a Total Organic Carbon (TOC) analyzer (Shimadzu, Kyoto, Japan). Organic anions were determined through a HPLC (Agilent Technologies, Tokyo, Japan) process. A UV detector (SPD-20A) monitored at $210 \mathrm{~nm}$ for the analysis of organic anions, the injection volume was $10 \mu \mathrm{L}$ and sample components were separated using a ZORBAX SB-Aq $(4.6 \times 250 \mathrm{~mm}$, $5 \mu \mathrm{m})$ StableBond analytical column (Agilent, Delaware, USA) at a $35^{\circ} \mathrm{C}$ column oven temperature and a 10 min running time. The mobile phase was $1 \%$ acetonitrile $+99 \% 20 \mathrm{mM} \mathrm{NaHPO}_{4}, \mathrm{pH} 2.2$, at a flow rate of $1.0 \mathrm{~mL} \mathrm{~min}{ }^{-1}$. The organic anions were identified by comparing their retention times with standards and their concentrations were determined according to their standard curves.
GC-MS and HPLC-ELSD analysis of sugars in rhizosphere extracts

Another subsample of $45 \mathrm{~mL}$ rhizosphere extract (frozen with liquid nitrogen) was freeze-dried for 2 days; the dried residue was re-suspended in $5 \mathrm{~mL}$ of deionized water and freeze-dried again, and then redissolved in $2 \mathrm{~mL}$ of cold methanol (Luo et al. 2017). The sample was blown to dryness under a gentle $\mathrm{N}_{2}$ flow, and then was derivatized by $250 \mu \mathrm{L}$ salinization solution (Bis(trimethylsilyl)trifluoroacetamid to pyridine ratio, 5:1) under $75{ }^{\circ} \mathrm{C}$ water bath for $1.0 \mathrm{~h}$ (Liu et al. 2015). The solution was filtered through a 0.45$\mu \mathrm{m}$ membrane filter and then analyzed by GC-MS.

Silylated supernatants were analyzed by GC-MS (Agilent Technologies, Agilent 7890A along with Agilent 5975C, USA) using a DB-5MS capillary column $(30 \mathrm{~m} \times 0.25 \mathrm{~mm}, 0.25 \mu \mathrm{m}$ film thickness; Agilent Technologies, USA). The gas chromatographic conditions were as follows: helium was used as a carrier gas at a flow rate of $1.0 \mathrm{~mL} \mathrm{~min}^{-1}$; the oven initial temperature was $40{ }^{\circ} \mathrm{C}$ for $2 \mathrm{~min}$, then increased to $200{ }^{\circ} \mathrm{C}$ at a rate of $5{ }^{\circ} \mathrm{C} \mathrm{min}-1$, then at a rate of $20{ }^{\circ} \mathrm{C} \min ^{-1}$ up to $270{ }^{\circ} \mathrm{C}$. Injections of $1 \mu \mathrm{L}$ were made in a splitless mode. The mass spectrometric system was set as follows: the ion source temperature was $230{ }^{\circ} \mathrm{C}$, full scan mode with a scan range of $\mathrm{m} / \mathrm{z}$ 60-640, and mass spectra were generated at $70 \mathrm{eV}$. Spectrum acquisition was realized $7 \mathrm{~min}$ after injection in order to avoid saturation of the detector. Compounds were subjected to NIST11 library search and data were analyzed by using MSD ChemStation software (Agilent, version G1701EA E.02.02.1431).

HPLC-Evaporative Light Scattering Detection (HPLC-ELSD) was further employed (Bernardo et al. 2008; Lindqvist et al. 2018) to identify sugars in rhizosphere extracts, with $1 \mathrm{mg} \mathrm{mL}^{-1}$ of glucose, galactose, fructose, sucrose and fucose as standards. A column Hi-Plex $\mathrm{Pb}(300 \mathrm{~mm} \times 7.7 \mathrm{~mm}$, Agilent, Delaware, USA) with HPLC grade water as the eluent at the flow rate of $0.6 \mathrm{~mL} \mathrm{m^{-1 }}$ was used. Sugar compounds were identified by comparison of HPLC retention times with those from standards.

Rhizosphere bacterial DNA extraction and 16S rRNA sequencing

Bacterial DNA was extracted from $0.2 \mathrm{~g}$ of fresh rhizosphere growth media using Powersoil ${ }^{\mathrm{TM}}$ DNA 
isolation kits (MoBio, San Diego, CA, USA) according to the manufacturer's instructions. The quality and quantity of the DNA extracts were checked using a spectrophotometer (Nanodrop, PeqLab, Germany). The V3-V4 region of the bacterial 16S rRNA gene was amplified using the forward primer $338 \mathrm{~F}\left(5^{\prime}\right.$-ACT CCTACGGGAGGCAGCA-3') and the reverse primer 806R (5'-GGACTACHVGGGTWTCTAAT-3'). Purified amplicons were pooled, and pair-end sequenced on the Illumina MiSeq platform, Miseq-PE250 (Personalbio ${ }^{\circledR}$, Shanghai, China). The raw reads were analyzed using QIIME software (version 1.7.0, http:// qiime.org/) to trim off adaptors, barcodes, primers and low quality reads. Sequences were clustered into operational taxonomic units (OTUs) by setting a 97\% similarity (Huang et al. 2017). The Bray-Curtis distance-based dissimilarity distance, Simpson and Chaol diversity index, principal coordinate analysis (PCoA) and a Venn diagram with shared and unique OTUs were performed on the Genescloud platform of Personalbio ${ }^{\circledR}$ to evaluate the bacterial community differences between non-ectomycorrhizal control and ectomycorrhizal treatment samples, as well as MetagenomeSeq analyses of enriched core bacterial compositions. Raw sequence data have been deposited in the NCBI Sequence Read Archive database under the bioproject identifier PRJNA662162.

\section{Statistical analysis}

Data (means $\pm \mathrm{SE}, n=4)$ were statistically analyzed by $R$ software (version 3.2.3). One-way analysis of variance for independent samples was performed. Pearson correlation analysis (for all analyzed samples, $n=8$ ) was used to examine the correlations between the relative abundance of OTUs and measured plant and soil parameters including photosynthetic parameters, leaf nutrient concentrations, leaf water content and rhizosphere $\mathrm{pH}$, phosphatases activity and rhizosphere exudates. Data on leaf $\mathrm{C}, \mathrm{N}$, $\mathrm{P}$ concentration and leaf water content were transformed to $\mathrm{C} \%, \mathrm{~N} \%, \mathrm{P} \%$ and leaf water $\%$ (mass ratio) before Pearson correlation analysis. Statistical significance for Pearson correlation was determined by pairwise two-sided comparisons. The PCoA analysis was based on Bray-Curtis distance at the OTU level and the MetagenomeSeq analysis was performed based on $-\log 10$ (adj P value) of the relative abundance at the OTU level. A significance $\alpha$ level of 0.05 was used.

\section{Results}

Leaf photosynthesis and nutrient concentration responses

Compared to the control, ectomycorrhizal (T. melanosporum) colonization enhanced leaf photosynthetic rate $(+69 \%)$ and $\mathrm{P}$ concentration $(+94 \%)$, decreased $\mathrm{K}$ concentration (- 26\%), but did not affect leaf stomatal conductance, transpiration rate, intercellular $\mathrm{CO}_{2}$ concentration, leaf $\mathrm{C}, \mathrm{N}, \mathrm{Ca}, \mathrm{Mg}, \mathrm{Fe}$ concentrations, nor leaf water content (Fig. 1 and Table S1). The average leaf $\mathrm{N}$ : $\mathrm{P}$ ratios were 13.03 and 7.87 for the control and ectomycorrhizal seedlings, respectively.

Rhizosphere $\mathrm{pH}$, TOC, organic anions and phosphatase activity

The average rhizosphere $\mathrm{pH}$ of mycorrhizal plants was significantly higher by 0.4 units $(P<0.05)$ than that of the control seedlings (Fig. 2a). Tuber melanosporum colonization significantly increased TOC in the rhizosphere by $76 \%$ (Fig. 2b). The accumulation of organic anions in the rhizosphere varied significantly, and fewer organic anions were detected in the rhizosphere of ectomycorrhizal than in that of control seedlings. Tartrate and oxalate were detected with tartrate being the dominant organic anion. Rhizosphere tartrate was significantly decreased under ECM while rhizosphere oxalate was not affected by ECM colonization (Fig. 2c). Rhizosphere alkaline phosphatase activity (ALP) was not affected by ECM symbiosis, but significantly higher $(+33 \%)$ rhizosphere acid phosphatase activity (ACP) was detected in ECM than in control seedlings (Fig. 2d).

Sugars in the rhizosphere

Since ECM colonization decreased rhizosphere organic anions but increased TOC (Fig. 2b, c), GC-MS was employed to determine the compounds being significantly increased in the extract of ECM rhizosphere. GC-MS detected a major peak corresponding to mannose/glucose/fructose and/or galactose in two of four ECM rhizosphere extracts but not in any of the control samples (Fig. S1). Furthermore, 

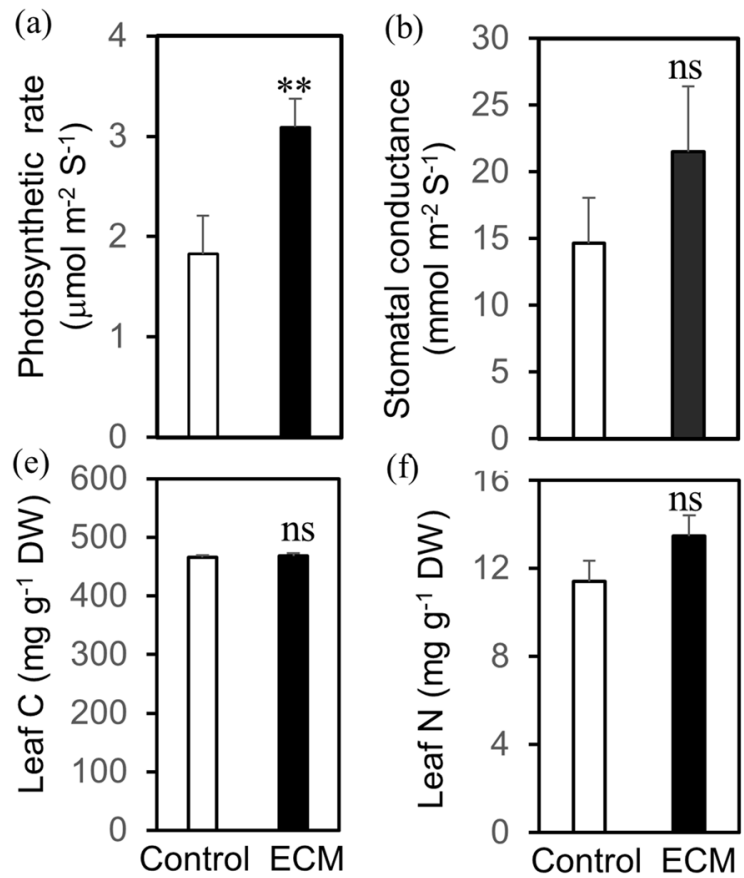

(f)

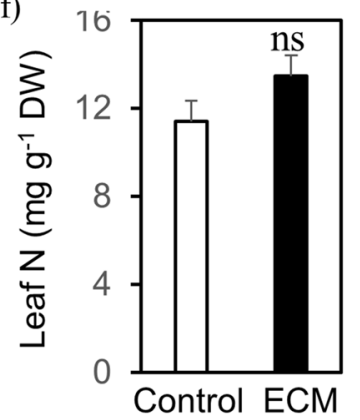

Fig. 1 Responses of leaf photosynthetic parameters and leaf nutrient concentrations to T. melanosporum ectomycorrhizal (ECM) colonization to Q. mongolica seedlings. a Mean leaf photosynthetic rate. b Stomatal conductance. c Transpiration

HPLC-ELSD confirmed the presence of galactose and other unidentified sugars in these two ECM samples (Fig. S2).

Rhizosphere bacterial communities

Bacterial community analysis indicated significant differences in $\beta$-diversity (dissimilarity distance, Fig. 3a) but not in Chao 1 and Simpson index ( $\alpha$ diversity, Fig. 3b); control and ECM samples were clearly defined by the PCoA (Fig. 3c). A total of 29,934 OTUs were displayed and only about $10 \%$ OTUs were shared by both the control and ECM seedlings (Fig. 3d). Compared to the control, a significantly greater relative abundance of actinobacteria at the phylum level $(P<0.05)$ was found (Fig. 4a), and significantly more abundant bacterial groups at the OTU level (order or genus equivalent) were shown under ECM by the MetagenomeSeq analysis $(P<0.05$, Fig. 4b). Pearson correlation analysis revealed significant correlations between the relative abundance of actinobacteria and amount of TOC $(\mathrm{r}=0.83, P=0.01$,

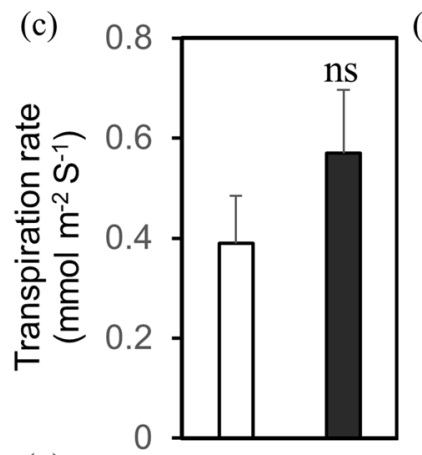

(g)
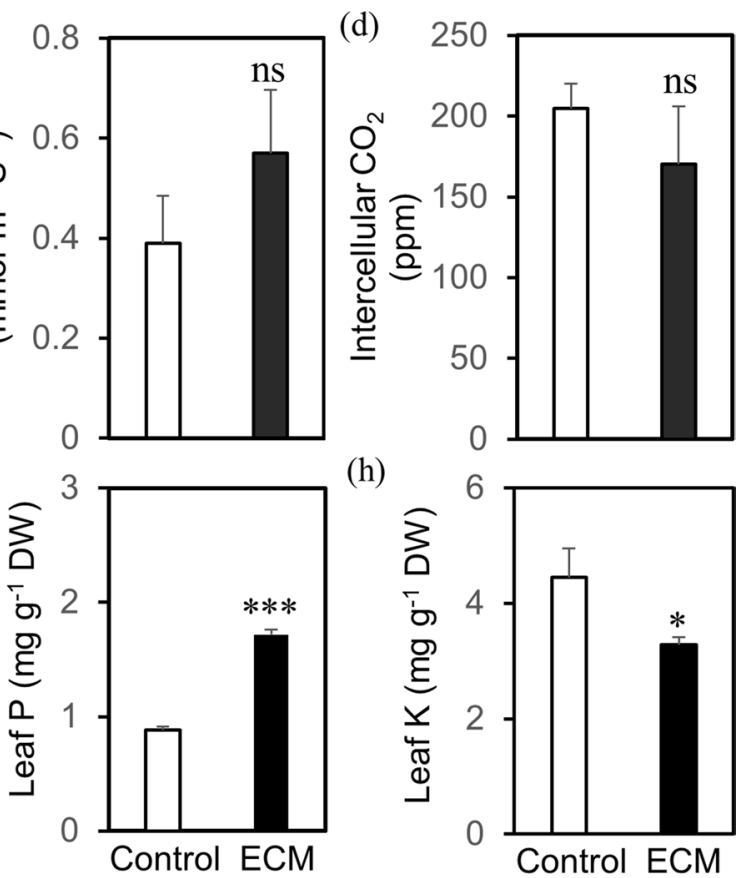

(h)

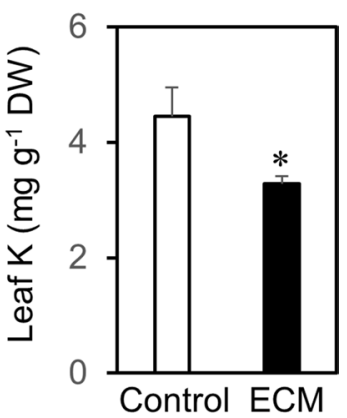

rate. d Intercellular $\mathrm{CO}_{2}$ concentration. e Leaf $\mathrm{C}$ concentration. f Leaf $\mathbf{N}$ concentration. $\mathbf{g}$ Leaf $\mathrm{P}$ and $\mathbf{h}$ Leaf $\mathrm{K}$ concentration. Error bars indicate SE $(n=4) . * P<0.05$; $* * P<0.01$; $* * * P<0.001 ;$ ns, no significant difference

$n=8)$ and tartrate $(\mathrm{r}=-0.72, P=0.04, n=8)$ in the rhizosphere.

The 20 most abundant OTUs were classified as Bauldia, Chryseolinea, Falvobacterium, Haliangium, Pedomicrobium, Pseudomonas, Saccharimonadales and unnamed taxa denoted as A4b, Amb-16S-1323, Blrii41, IMCC26256, JG30-KF-CM66, KD4-96, MND1, PLTA13, S085, Subgroup_6, Subgroup_17, Subgroup_22 and SWB02 (Fig. 5a). Among those OTUs, significant different abundances in Amb16S-1323, IMCC26256, PLTA13 and SWB02 were detected between colonized and un-colonized rhizosphere samples. The Pearson correlation analysis (as shown in Fig. 4b) showed that rhizosphere TOC positively correlated with Flavobacterium but negatively with Subgroup_17 and SWB02; rhizosphere tartrate positively correlated with Bauldia and SWB02, but negatively with Flavobacterium; rhizosphere oxalate correlated positively with Blrii41. In addition, rhizosphere $\mathrm{pH}$ positively correlated with PLTA13 but negatively with Bauldia, while rhizosphere acid phosphatase activity positively correlated with Amb-16S-1323. 
Fig. 2 Responses of rhizosphere characteristics to $T$. melanosporum ectomycorrhizal (ECM) colonization to $Q$. mongolica seedlings. a Rhizosphere $\mathrm{pH}$. b Total organic carbon in rhizosphere extract. $\mathbf{c}$ Rhizosphere carboxylates. d Rhizosphere acid and alkaline phosphatase (S-ACP and S-ALP) activities. Error bars indicate SE $(n=4)$. $* P<0.05 ; * * P<0.01$ $* * * P<0.001 ;$ ns, no significant difference (a)

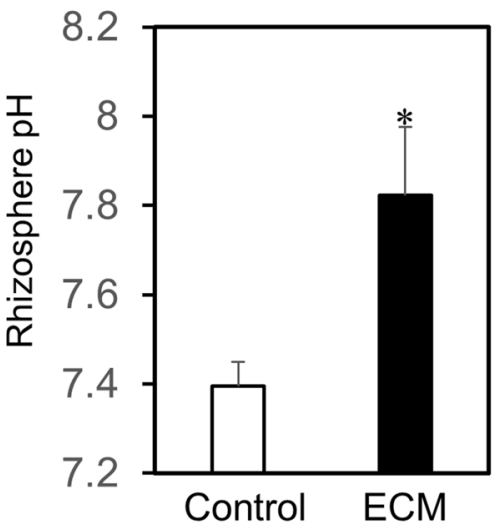

(c)

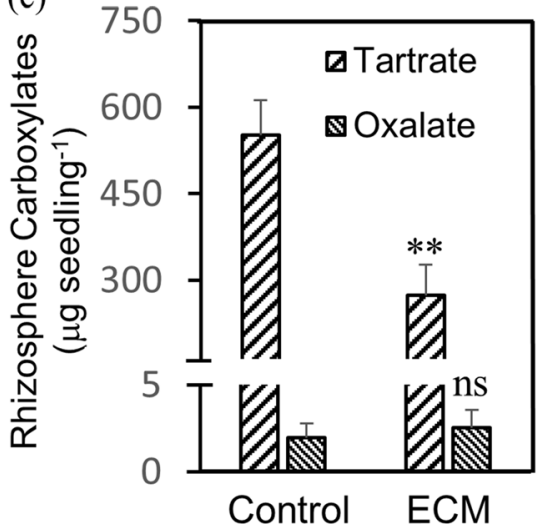

(b)

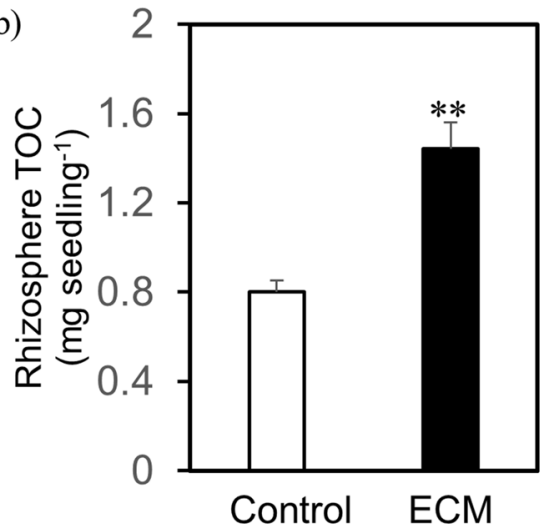

(d)

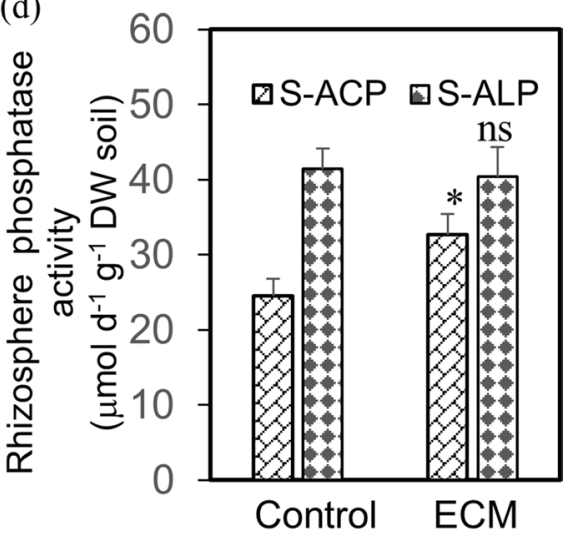

\section{Discussion}

In this study we found that $T$. melanosporum ectomycorrhizal colonization significantly increased leaf photosynthetic rate and rhizosphere TOC exudates (whose organic anions component was however reduced), as well as the rhizosphere $\mathrm{pH}$ and acid phosphatase activity. Tuber melanosporum ectomycorrhizal colonization of $Q$. mongolica also shifted rhizosphere bacterial communities towards a community that was enriched with actinobacteria. Moreover, the relative abundances of rhizosphere actinobacteria and OTUs Bauldia, Blrii41, Flavobacterium, SWB02 or Subgroup_17 was correlated with rhizosphere amounts of TOC and organic anions indicating that root exudates as a potential mechanism for this shift. The implications of these findings and other points of interest are discussed below.
Effects of the substrate and plant cultivation system

The present study used a substrate instead of real forest soil to grow plants in a greenhouse. Although the obtained results may not reflect the situation under natural conditions, this plant cultivation system has several advantages, and these results have many implications relevant to ectomycorrhizal symbiosis. First, the substrate used is reliable for a practical T. melanosporum ECM synthesis with oak seedlings, an essential prerequisite for further studies (see Wang et al. 2019), although Tuber mycorrhizas might regress or disappear after several to 21 years of transplanting to the field (Guerin-Laguette et al. 2013). Second, the components of peat moss (Jiffy, The Netherlands, $70 \%$ organic $\mathrm{C}, 0.8 \%$ organic $\mathrm{N}, \mathrm{pH}$ 5.0-6.0) and pine bark in the substrate were similar to those found in peatlands or surface layers of forest soils. Finally, the effects of other mycorrhizas that 
Fig. 3 Responses of rhizosphere bacterial community structure to T. melanosporum ectomycorrhizal (ECM) colonization to $Q$. mongolica seedlings. a Dissimilarity distance. $\mathbf{b}$ Chao 1 and Simpson indexes. c Principal coordinate analysis $(\mathrm{PCoA})$ of the bacterial communities in the rhizosphere. d Venn figure showing shared and unique operational taxonomic units (OTUs) between control and ECM samples

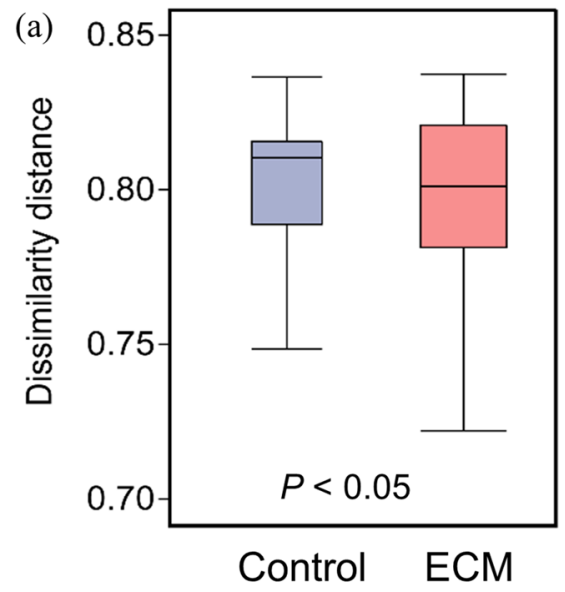

(b)
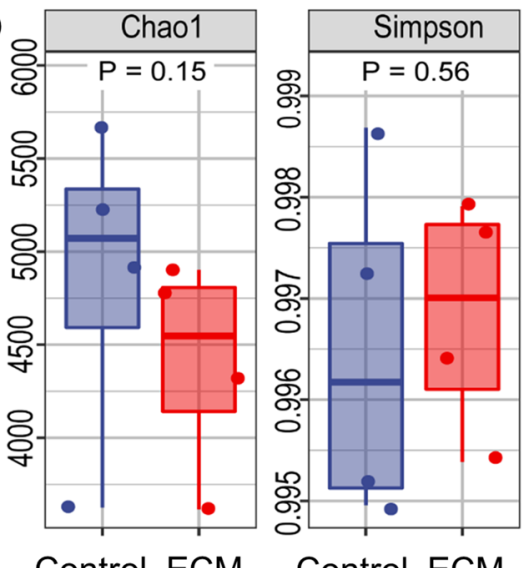

Control ECM

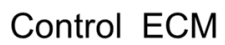

(c)

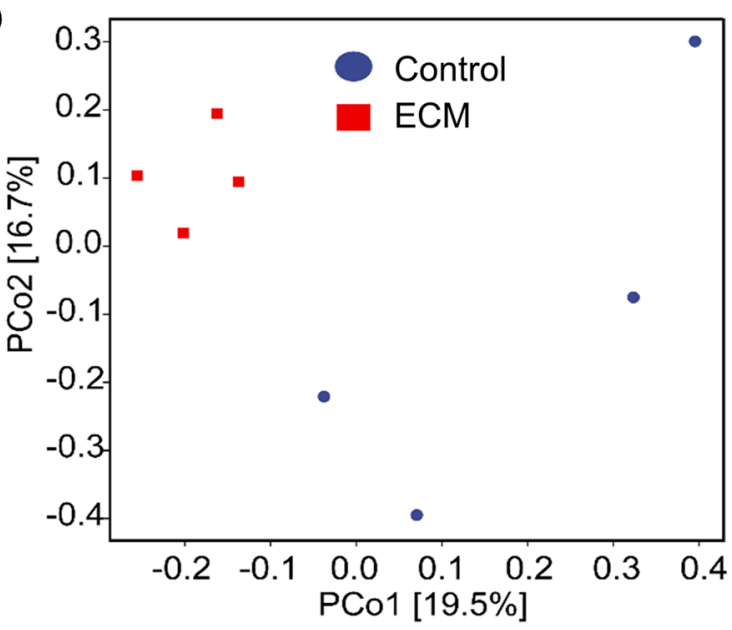

(d)

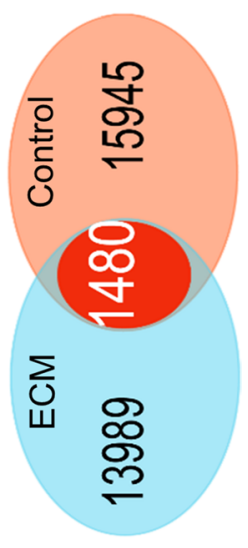

often exist as complex fungal communities in natural conditions (Zhang et al. 2019) could be excluded in our system since no other ECM species was detected on any roots (Wang et al. 2019).

Tuber melanosporum colonization enhances photosynthesis and nutrient acquisition

Studies have reported that ECM colonization can enhance photosynthesis of Pinus taeda, P. densiflora and Eucalyptus camaldulensis seedlings (Reid et al. 1983; Dixon and Hiol-Hiol 1992; Choi et al. 2005), as well as of Quercus ilex seedlings colonized by $T$. melanosporum (Nardinia et al. 2000). Similarly, we found T. melanosporum ECM significantly increased the photosynthetic rate of $Q$. mongolica seedlings (Fig. 1a), hence, supporting our first hypothesis. Interestingly, an enhanced $\mathrm{C}$ assimilation rate did not result in a significantly increased leaf $\mathrm{C}$ concentration in ECM seedlings in our study (Fig. 1a vs. e). The assimilated $\mathrm{C}$ might have been allocated to biomass production, root exudates, and/or mycorrhizal tissues (Liu et al. 2019).

It is known that ECM colonization improves host plant nutrient acquisition, especially for $\mathrm{P}$ (Nehls and Plassard 2018). Similar to our study, four-monthold $P$. contorta seedlings inoculated with Pisolithus tinctorius or Suillus granulatus showed significantly greater foliar $\mathrm{P}$, but not $\mathrm{N}$, concentrations compared to non-mycorrhizal seedlings (Reid et al. 1983). However, considering the increased number of leaves and mean leaf dimension observed in Wang et al. (2019) and the measured nutrient concentration in the present study (Fig. 1f, g and Table S1), T. melanosporum ECM improved N, P, Mg and Fe uptake of Q. mongolica seedlings. Effect of T. melanosporum colonization on leaf $\mathrm{K}$ concentration has been shown to depend on the host plant species (Domínguez Núñez et al. 2006, 


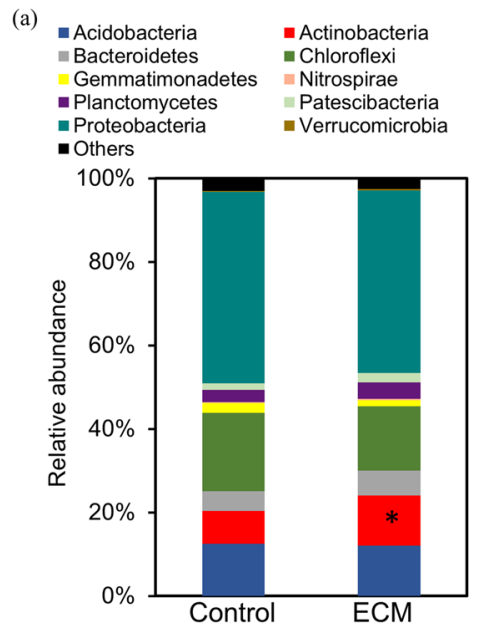

(b)

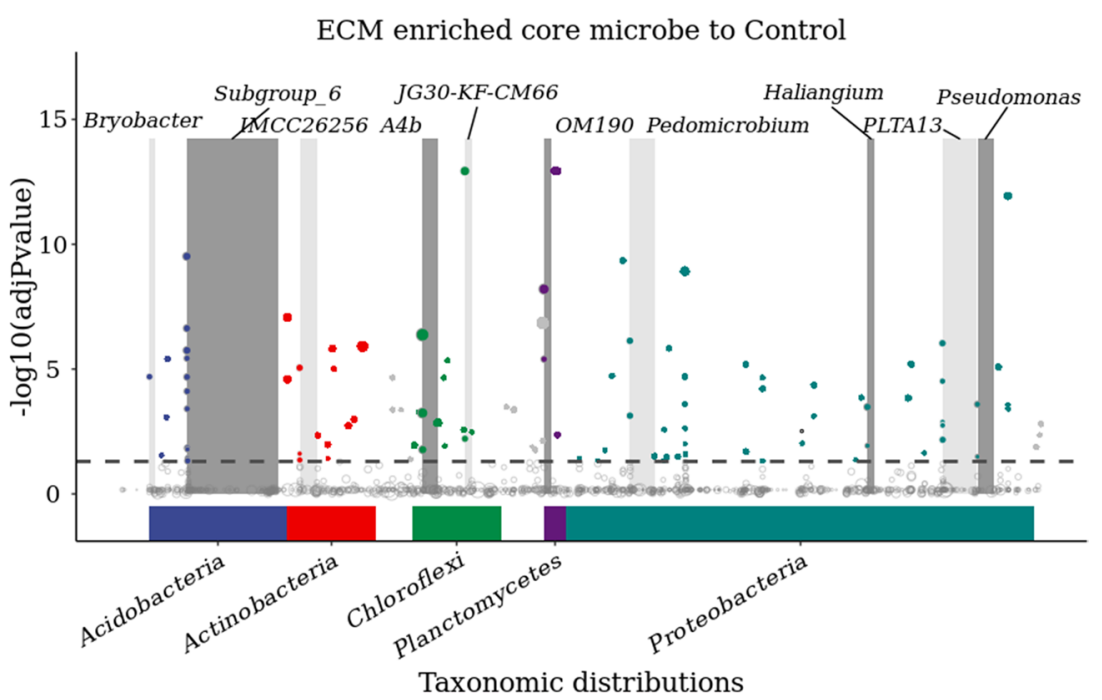

Fig. 4 Responses of rhizosphere bacterial community composition to T. melanosporum ectomycorrhizal (ECM) colonization to $Q$. mongolica seedlings. a Relative abundance of bacterial composition at the phylum level. b Tuber melanosporum

2008), and we found decreased leaf $\mathrm{K}$ concentration in T. melanosporum-colonized $Q$. mongolica seedlings (Fig. 1h). Overall, this supports our hypothesis that T. melanosporum ECM would improve the host's nutrient acquisition.

Tuber melanosporum mycorrhization increases amounts of rhizosphere TOC but reduces organic anions

Increased rhizosphere TOC and acid phosphatase activity were induced by T. melanosporum ECM in this study, which was consistent with results found in other ECMs (Taniguchi et al. 2008; Cairney 2012). The increased TOC might be due to monosaccharide root exudates such as galactose, and mycorrhizal hyphae-exuded sugar like fructose could attract $\mathrm{P}$ solubilizing bacteria to promote $\mathrm{P}$ mobilization and uptake by plant (Zhang et al. 2018). Alternatively, sugars derived from the decomposition of mycelia could also explain this result. Moreover, polysaccharides hydrolyzed by soil bacteria might also contribute to the increased TOC, as discussed below.

Fewer organic anions in the ECM rhizosphere compared to non-ECM control plants were detected in this study (Fig. 2c). We see two possible reasons: (1)
ECM colonization enriched (color dots indicating significant OTUs) core bacterial composition, compared to that of control samples

our uninoculated seedlings, with a high leaf $\mathrm{N}$ : P ratio and a low leaf $\mathrm{P}$ concentration, might have slightly suffered from P deficiency (Güsewell 2004), which could induce organic anions to be released from roots to mobilize less-available $\mathrm{P}$ (Wang and Lambers 2020); and (2) mycorrhized plants may exhibit tradeoffs in photosynthetically assimilated C allocation (Chen et al. 2016; Wang and Lambers 2020). Colonization by mycorrhizal fungi could decrease rootreleased organic anions: this has been experimentally confirmed in both arbuscular (Ryan et al. 2012; Nazeri et al. 2013; Del-Saz et al. 2017) and ectomycorrhizal (Meier et al. 2013; van Scholl et al. 2006) plants. Van Scholl et al (2006) also found that oxalate exudation in P. sylvestris roots decreased when these were colonized by Hebeloma longicaudum but increased when colonized by Paxillus involutus and Piloderma croceum, suggesting that the effect of ECM on exudation of organic anions might also be ECM speciesdependent. Release of organic anions would result in a decrease in rhizosphere $\mathrm{pH}$ (Hinsinger 2001; Casarin et al. 2004). In contrast, decreased organic anions might lead to a slightly higher rhizosphere $\mathrm{pH}$ by $T$. melanosporum mycorrhization in our study (Fig. 2a). Other studies suggested that mycorrhizas could release protons and $\mathrm{C}$-containing substances such as 


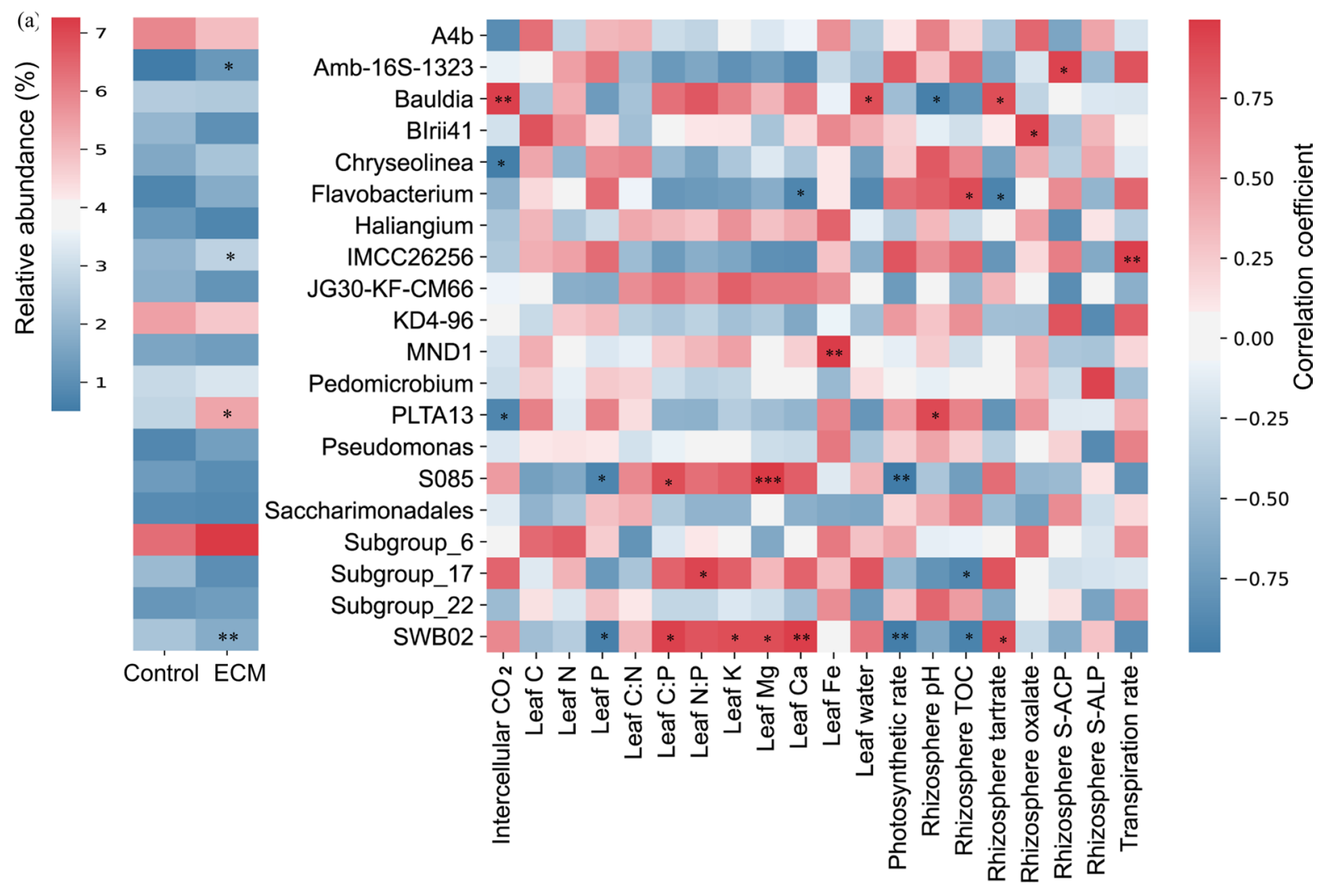

Fig. 5 Heatmap of the relative abundance of the TOP 20 most abundant OTUs (agglomerated to genus or order, a) and Pearson correlation analysis between the dominant OTUs and plant or soil parameters $(\mathbf{b})$. $* P<0.05 ; * * P<0.01 ; * * * P<0.001$

organic anions to mobilize soil nutrients (Rigou et al. 1995; Cairney 2011).

While a decrease in organic anions we detected, our hypothesis (2) that T. melanosporum mycorrhization might reduce rhizosphere $\mathrm{C}$ exudates was not fully supported since an increase in TOC was detected in the rhizosphere extract of T. melanosporum ECM seedlings.

Tuber melanosporum mycorrhization alters rhizosphere bacterial communities

Various soil microbes are involved in the life cycle of T. melanosporum and they may play key roles in the formation of T. melanosporum ECMs and ascocarps (Mello et al. 2013; Splivallo et al. 2015; Chen et al. 2019). In our study, the substrate was autoclaved before use. However, the plant cultivation was open to non-sterile environment for more than 3 years and the spore slurry for inoculation was not sterilized, thus the bacterial communities sequenced here were 'de novo' assembled and enriched from both the environment and ascocarps. A recent study reported that $T$. melanosporum mycorrhization harbored distinct bacterial communities with an enrichment in Alpha- and Gamma- proteobacteria, compared to the bulk soil (Deveau et al. 2016). We found that proteobacteria were the dominant phylum in the rhizosphere of both control and T. melanosporum ECM seedlings. Furthermore, actinobacteria were enriched by $T$. melanosporum mycorrhization in our system (Fig. 4a). Some soil actinobacteria have a strong ability to hydrolyze a wide range of polysaccharides such as cellulose, chitin and xylan (Barka et al. 2016). Thus actinobacteria might contribute to the increased TOC in the ECM rhizosphere, which could partly explain the positive correlation between rhizosphere TOC and the relative abundance of actinobacteria. Some actinobacteria can fix $\mathrm{N}$ and solubilize minerals in 
soil (Glick 1995), hereby increasing uptake of $\mathrm{N}$ and other nutrients in ECM seedlings compared with control plants.

There is a diversity of membrane transport systems in bacteria for the uptake of different C-compounds (Jones et al. 1996), thus changes in rhizosphere TOC and organic anions may lead to changes in overall microbial diversity. The genus Bauldia, which may have different potential to utilize $\mathrm{C}$ source (Yee et al. 2010), was overrepresented in the rhizosphere of ratooning sugarcane (Gao et al. 2019). Flavobacterium was quite often detected in the plant rhizosphere, and it may increase carbohydrase activity (Mawdsley and Burns 1994). Blrii41 has been reported to be abundant in organic soils and enriched in maize roots under chilling conditions (Beirinckx et al. 2020). SWB02 is known to play important roles in denitrification (Iannacone et al. 2020), and Subgroup_17 has been shown to have strong positive correlation with soil available N (Yi et al. 2019). Thus, the high content of organic matter in our substrate, high amounts of rhizosphere TOC and improved $\mathrm{N}$ uptake by ECM seedlings could partly explain the increased abundance of Blrii41, Bauldia, Flavobacterium and Subgroup_17 and decreased abundance of SWB02 detected in the ECM rhizosphere, respectively. Collectively, these enriched groups of bacteria are important to soil $\mathrm{C}$ and $\mathrm{N}$ transformations. Altered rhizosphere $\mathrm{C}$ exudates, resulting from T. melanosporum ectomycorrhizal colonization, might drive bacterial communities and $\mathrm{N}$ transformations as reported previously (Landi et al. 2006; Meier et al. 2017; Zhalnina et al. 2018) and in support of our hypothesis.

\section{Conclusion}

Tuber melanosporum mycorrhization significantly enhanced leaf $\mathrm{C}$ assimilation and root $\mathrm{C}$ exudation (TOC), promoted nutrient acquisition and altered rhizosphere bacterial communities of $Q$. mongolica seedlings grown in a previously sterilized peat-based substrate. These results indicate that T. melanosporum ECM can regulate the plant carbon economy and bacterial community structure in the rhizosphere. These results provide insights into a better understanding of $\mathrm{C}$ allocation, ECM-facilitated plant growth and nutrient cycling in truffle orchards and natural forests. However, it should be noted that this is a small study with four replicates, thus, we propose additional studies using diverse host trees, ectomycorrhizal symbionts and growth conditions to verify or reinforce these findings.

Acknowledgements We thank Yunnan High Level Talent Introduction Plan, as well as Fei Li, Liangliang Yue, Zhongfu Zhang, Wei Chang and Rui Yan for various supports. We also appreciate Prof. Gregory Bonito (Michigan State University) for careful reading and language editing.

Authors contribution YW carried out the data collection and analysis, and wrote the manuscript. YW and FY designed and instructed the study. RW and AGL contributed to plant materials. BL helped with HPLC, HPLC-ELSD and GC-MS analysis. AGL and $\mathrm{XH}$ discussed the results and revised the manuscript.

Funding This work was supported by Kunming Institute of Botany, CAS (Y9627111K1), National Natural Science Foundation of China (31901204) and Guizhou Science and Technology Program (No. 4002, 2018).

Data availability 16S rRNA raw sequence data have been deposited in the NCBI Sequence Read Archive database under the bioproject identifier PRJNA662162.

\section{Declarations}

Conflict of interest The authors declare that they have no conflict of interest.

Consent to participate All authors contributed to the manuscript.

Consent for publication All authors approved the manuscript.

\section{References}

Albornoz FE, Dixon KW, Lambers H (2021) Revisiting mycorrhizal dogmas: are mycorrhizas really functioning as they are widely believed to do? Soil Ecol Lett 3:73-82

Anderson IC, Cairney JW (2007) Ectomycorrhizal fungi: exploring the mycelial frontier. FEMS Microbiol Rev 3:388-406

Barka EA, Vatsa P, Sanchez L et al (2016) Taxonomy, physiology, and natural products of actinobacteria. Microbiol Mol Biol Rev 80:1-43

Bernardo A, Martinez S, Álvarez M, Fernandez A, Lopze M (2008) The composition of two Spanish pepper varieties (Fersno de la vega and Benavente-los Valles) in different ripening stages. J Food Qual 31:701-716

Beirinckx S, Viaene T, Haegeman A et al (2020) Tapping into the maize root microbiome to identify bacteria that 
promote growth under chilling conditions. Microbiome 8:54. https://doi.org/10.1186/s40168-020-00833-w

Bulgarelli D, Schlaeppi K, Spaepen S, Loren V, van Themaat E, Schulze-Lefert P (2013) Structure and functions of the bacterial microbiota of plants. Annu Rev Plant Biol 64:807-838

Cairney JWG (2011) Ectomycorrhizal fungi: the symbiotic route to the root for phosphorus in forest soils. Plant Soil 344:51-71

Cairney JWG (2012) Extramatrical mycelia of ectomycorrhizal fungi as moderators of carbon dynamics in forest soil. Soil Biol Biochem 47:198-208

Casarin V, Plassard C, Hinsinger P, Arvieu JC (2004) Quantification of ectomycorrhizal fungal effects on the bioavailability and mobilization of soil $\mathrm{P}$ in the rhizosphere of Pinus pinaster. New Phytol 163:177-185

Chen J, Li JM, Tang YJ, Xing YM, Qiao P, Li Y, Liu PG, Guo SX (2019) Chinese black truffle-associated bacterial communities of Tuber indicum from different geographical regions with nitrogen fixing bioactivity. Front Microbiol. https://doi.org/10.3389/fmicb.2019.02515

Chen W, Koide RT, Adams TS, DeForest JL, Cheng L, Eissenstat DM (2016) Root morphology and mycorrhizal symbioses together shape nutrient foraging strategies of temperate trees. Proc Natl Acad Sci 113:8741-8746

Choi DS, Quoreshi AM, Maruyama Y, Jin HO, Koike T (2005) Effect of ectomycorrhizal infection on growth and photosynthetic characteristics of Pinus densiflora seedlings grown under elevated $\mathrm{CO}_{2}$ concentrations. Photosynthetica 43:223-229

Crowley DE, Maronek DM, Hendrix JW (1986) Effect of slow release fertilizers on formation of mycorrhizae and growth of container grown pine seedlings. J Environ Hortic 4:97-101

Del-Saz NF, Romero-Munar A, Cawthray GR et al (2017) Arbuscular mycorrhizal fungus colonization in Nicotiana tabacum decreases the rate of both carboxylate exudation and root respiration and increases plant growth under phosphorus limitation. Plant Soil 416:97-106

Deveau A, Antony-Babu S, Le Tacon F, Robin C, Frey-Klett P, Uroz S (2016) Temporal changes of bacterial communities in the Tuber melanosporum ectomycorrhizosphere during ascocarp development. Mycorrhiza 26:389-399

Dixon RK, Hiol-Hiol F (1992) Gas exchange and photosynthesis of Eucalyptus camaldulensis seedlings inoculated with different ectomycorrhizal symbionts. Plant Soil 147:143-149

Domínguez Núñez JA, Planelles González R, Rodríguez Barreal JA, Saiz de Omeñaca González JA (2008) The effect of Tuber melanosporum Vitt. mycorrhization on growth, nutrition, and water relations of Quercus petraea Liebl., Quercus faginea Lamk., and Pinus halepensis Mill seedlings. New For 35:159-171

Domínguez Núñez JA, Serrano JS, Barreal JAR, González JASO (2006) The influence of mycorrhization with Tuber melanosporum in the afforestation of a Mediterranean site with Quercus ilex and Quercus faginea. For Ecol Manage 231:226-233

Donnini D, Gargano ML, Perini C et al (2013) Wild and cultivated mushrooms as a model of sustainable development. Plant Biosyst 147:226-236
Gao X, Wu Z, Liu R, Wu J, Zeng Q, Qi Y (2019) Rhizosphere bacterial community characteristics over different years of sugarcane ratooning in consecutive monoculture. Biomed Res Int. https://doi.org/10.1155/2019/4943150

Guerin-Laguette A, Cummings N, Butler RC, Willows A, Williams NH, Li S, Wang Y (2014) Lactarius deliciosus and Pinus radiata in New Zealand: towards the development of innovative gourmet mushroom orchards. Mycorrhiza 24:511-523

Guerin-Laguette A, Cummings N, Hesom-Williams N, Butler R, Wang Y (2013) Mycorrhiza analyses in New Zealand truffières reveal frequent but variable persistence of Tuber melanosporum in co-existence with other truffle species. Mycorrhiza 23:87-98

Güsewell S (2004) N : P ratios in terrestrial plants: variation and functional significance. New Phytol 164:243-266

Glick BR (1995) The enhancement of plant growth by freeliving bacteria. Can J Microbiol 41:109-117

Haichar FZ, Santaella C, Heulin T, Achouak W (2014) Root exudates mediated interactions belowground. Soil Biol Biochem 77:69-80

Hinsinger P (2001) Bioavailability of soil inorganic P in the rhizosphere as affected by root-induced chemical changes: a review. Plant Soil 237:173-195

Huang J, Cao C, Yan C, Liu J, Hu Q, Guan W (2017) Impacts of silver nanoparticles on the nutrient removal and functional bacterial community in vertical subsurface flow constructed wetlands. Biores Technol 243:1216-1226

Iannacone F, Di Capua F, Granata F, Gargano R, Esposito G (2020) Simultaneous nitrification, denitrification and phosphorus removal in a continuous-flow moving bed biofilm reactor alternating microaerobic and aerobic conditions. Bioresou Technol 310:123453

Jones DL, Prabowo AM, Kochian LV (1996) Kinetics of malate transport and decomposition in acid soils and isolated bacterial populations: the effect of microorganisms on root exudation of malate under Al stress. Plant Soil 182:239-247

Landi L, Valori F, Ascher J, Renella G, Falchini L, Nannipieri $P$ (2006) Root exudate effects on the bacterial communities, $\mathrm{CO}_{2}$ evolution, nitrogen transformations and ATP content of rhizosphere and bulk soils. Soil Biol Biochem 38:509-516

Lindqvist DN, Pedersen HÆ, Rasmussen LH (2018) A novel technique for determination of the fructose, glucose and sucrose distribution in nectar from orchids by HPLCELSD. J Chromatogr B 1081:126-130

Liu W, Hou J, Wang Q, Yang H, Luo Y, Christie P (2015) Collection and analysis of root exudates of Festuca arundinacea $\mathrm{L}$. and their role in facilitating the phytoremediation of petroleum-contaminated soil. Plant Soil 389:109-119

Liu Y, Ge T, Zhu Z et al (2019) Carbon input and allocation by rice into paddy soils: a review. Soil Biol Biochem 133:97-107

Luo Q, Wang S, Sun L, Wang H (2017) Metabolic profiling of root exudates from two ecotypes of Sedum alfredii treated with $\mathrm{Pb}$ based on GC-MS. Sci Rep. https://doi.org/10. 1038/srep39878

Lynch JP, Ho MD, Phosphorus L (2005) Rhizoeconomics:carbon costs of phosphorus acquisition. Plant Soil 269:45-56 
Mawdsley JL, Burns RG (1994) Inoculation of plants with a Flavobacterium species results in altered rhizosphere enzyme activities. Soil Biol Biochem 26(7):871-882

Meier IC, Avis PG, Phillips RP (2013) Fungal communities influence root exudation rates in pine seedlings. FEMS Microbiol Ecol 83:585-595

Meier IC, Finzi AC, Phillips RP (2017) Root exudates increase $\mathrm{N}$ availability by stimulating microbial turnover of fastcycling N pools. Soil Biol Biochem 106:119-128

Mello A, Ding GC, Piceno YM et al (2013) Truffle brûlés have an impact on the diversity of soil bacterial communities. Plos One 8(4):61945

Nardinia A, Salleo S, Tyree MT, Vertovec M (2000) Influence of the ectomycorrhizas formed by Tuber melanosporum Vitt. on hydraulic conductance and water relations of Quercus ilex L. seedlings. Ann for Sci 57:305-312

Nazeri NK, Lambers H, Tibbett M, Ryan MH (2013) Moderating mycorrhizas: Arbuscular mycorrhizas modify rhizosphere chemistry and maintain plant phosphorus status within narrow boundaries. Plant, Cell Environ 37:911-921

Nehls U, Plassard C (2018) Nitrogen and phosphate metabolism in ectomycorrhizas. New Phytol 220:1047-1058

Nguyen NH, Bruns TD (2015) The Microbiome of Pinus muricata ectomycorrhizae: Community assemblages, fungal species effects, and burkholderia as important bacteria in multipartnered symbioses. Microb Ecol 69:914-921

Pang J, Yang J, Lambers H, Tibbett M, Siddique KH, Ryan MH (2015) Physiological and morphological adaptations of herbaceous perennial legumes allow differential access to sources of varyingly soluble phosphate. Physiol Plant 154:511-525

Peterson RL, Massicotte HB, Melville LH (2004) Mycorrhizas: Anatomy and Cell biology. NRC Research Press, Canada

Raven JA, Lambers H, Smith SE, Westoby M (2018) Costs of acquiring phosphorus by vascular land plants: patterns and implications for plant coexistence. New Phytol 217:1420-1427

Reid CPP, Kidd FA, Ekwebelam SA (1983) Nitrogen nutrition, photosynthesis and carbon allocation in ectomycorrhizal pine. Tree root systems and their mycorrhizas. Springer, Dordrecht, pp 415-431

Rigou L, Mignard E, Plassard C, Arvieu JC, Remy JC (1995) Influence of ectomycorrhizal infection on the rhizosphere $\mathrm{pH}$ around roots of maritime pine (Pinus pinaster Soland in Ait.). New Phytol 130:141-147

Ryan MH, Tibbett M, Edmonds T, Suriyagoda LD, Lambers H, Cawthray GR, Pang J (2012) Carbon trading for phosphorus gain: the balance between rhizosphere carboxylates and arbuscular mycorrhizal symbiosis in plant phosphorus acquisition. Plant, Cell Environ 35:2170-2180

Smith SE, Read DJ (2008) Mycorrhizal symbiosis. Academic, New York

Splivallo R, Deveau A, Valdez N, Kirchhoff N, Frey-Klett P, Karlovsky P (2015) Bacteria associated with truffle-fruiting bodies contribute to truffle aroma. Environ Microbiol 17:2647-2660

Taniguchi T, Kataoka R, Futai K (2008) Plant growth and nutrition in pine (Pinus thunbergii) seedlings and dehydrogenase and phosphatase activity of ectomycorrhizal root tips inoculated with seven individual ectomycorrhizal fungal species at high and low nitrogen conditions. Soil Biol Biochem 40:1235-1243

van Scholl L, Hoffland E, van Breemen N (2006) Organic anion exudation by ectomycorrhizal fungi and Pinus sylvestris in response to nutrient deficiencies. New Phytol 170:153-163

Wang X (2012) Truffle Cultivation in China. Edible Ectomycorrhizal Mushrooms. Springer, Berlin, pp 227-240

Wang R, Guerin-Laguette A, Butler R, Huang LL, Yu FQ (2019) The European delicacy Tuber melanosporum forms mycorrhizae with some indigenous Chinese Quercus species and promotes growth of the oak seedlings. Mycorrhiza 29:649-661

Wang Y, Krogstad T, Clarke JL, Hallama M, Øgaard AF, EichGreatorex S, Kandeler E, Clarke N (2016) Rhizosphere organic anions play a minor role in improving crop species' ability to take up residual phosphorus $(\mathrm{P})$ in agricultural soils low in $\mathrm{P}$ availability. Front Plant Sci. https://doi. org/10.3389/fpls.2016.01664

Wang Y, Krogstad T, Clarke N, Øgaard AF, Clarke JL (2017) Impact of phosphorus on rhizosphere organic anions of wheat at different growth stages under field conditions. AoB Plants. https://doi.org/10.1093/aobpla/plx008

Wang Y, Lambers H (2020) Root-released organic anions in response to low phosphorus availability: recent progress, challenges and future perspectives. Plant Soil 447:135-156

Yi X, Yi K, Fang K, Gao H, Dai W, Cao L (2019) Microbial community structures and important sssociations between soil nutrients and the responses of specific taxa to ricefrog cultivation. Front Microbiol. https://doi.org/10.3389/ fmicb.2019.01752

Yee B, Oertli GE, Fuerst JA, Staley JT (2010) Reclassification of the polyphyletic genus Prosthecomicrobium to form two novel genera, Vasilyevaea gen. nov. and Bauldia gen. nov. with four new combinations: Vasilyevaea enhydra comb. nov., Vasilyevaea mishustinii comb. nov., Bauldia consociata comb. nov. and Bauldia litoralis comb. nov. Int J Syst Evol Microbiol 60:2960-2966

Zhalnina K, Louie KB, Hao Z et al (2018) Dynamic root exudate chemistry and microbial substrate preferences drive patterns in rhizosphere microbial community assembly. Nat Microbiol 3:470-480

Zhang L, Feng G, Declerck S (2018) Signal beyond nutrient, fructose, exuded by an arbuscular mycorrhizal fungus triggers phytate mineralization by a phosphate solubilizing bacterium. ISME J 12:2339-2351

Zhang Z, Yuan Y, Liu Q, Yin H (2019) Plant nitrogen acquisition from inorganic and organic sources via root and mycelia pathways in ectomycorrhizal alpine forests. Soil Biol Biochem 136:107517

Publisher's note Springer Nature remains neutral with regard to jurisdictional claims in published maps and institutional affiliations. 